\title{
Temperature Optimized Ammonia and Ethanol Sensing Using Ce Doped Tin Oxide Thin Films in a Novel Flow Metric Gas Sensing Chamber
}

\author{
K. Govardhan ${ }^{1}$ and Andrews Nirmala Grace ${ }^{2}$ \\ ${ }^{1}$ School of Electronics Engineering, VIT University, Vellore 632014, India \\ ${ }^{2}$ Centre for Nanotechnology Research, VIT University, Vellore 632014, India \\ Correspondence should be addressed to K. Govardhan; kgovardhan@vit.ac.in
}

Received 22 January 2016; Accepted 19 April 2016

Academic Editor: Kourosh Kalantar-Zadeh

Copyright (C) 2016 K. Govardhan and A. Nirmala Grace. This is an open access article distributed under the Creative Commons Attribution License, which permits unrestricted use, distribution, and reproduction in any medium, provided the original work is properly cited.

\begin{abstract}
A simple process of gas sensing is represented here using Ce doped tin oxide nanomaterial based thin film sensor. A novel flow metric gas chamber has been designed and utilized for gas sensing. Doping plays a vital role in enhancing the sensing properties of nanomaterials. Ce doped tin oxide was prepared by hydrothermal method and the same has been used to fabricate a thin film for sensing. The microstructure and morphology of the prepared materials were analysed by SEM, XRD, and FTIR analysis. The SEM images clearly show that doping can clamp down the growth of the large crystallites and can lead to large agglomeration spheres. Thin film gas sensors were formed from undoped pure $\mathrm{SnO}_{2}$ and Ce doped $\mathrm{SnO}_{2}$. The sensors were exposed to ammonia and ethanol gases. The responses of the sensors to different concentrations (50-500 ppm) of ammonia and ethanol at different operating temperatures $\left(225^{\circ} \mathrm{C}-500^{\circ} \mathrm{C}\right)$ were studied. Results show that a good sensitivity towards ammonia was obtained with Ce doped $\mathrm{SnO}_{2}$ thin film sensor at an optimal operating temperature of $325^{\circ} \mathrm{C}$. The Ce doped sensor also showed good selectivity towards ammonia when compared with ethanol. Pure $\mathrm{SnO}_{2}$ showed good sensitivity with ethanol when compared with Ce doped $\mathrm{SnO}_{2}$ thin film sensor. Response time of the sensor and its stability were also studied.
\end{abstract}

\section{Introduction}

Metal oxide semiconductor based thin and thick films have been widely used in gas sensors. Such materials possess good chemisorption based affinity towards a wide range of gases like $\mathrm{NH}_{3}, \mathrm{CH}_{4}$, and $\mathrm{H}_{2} \mathrm{~S}$ and Volatile Organic Compounds (VOC) with a detection ability up to a few ppm levels [1-5]. Among them, $\mathrm{SnO}_{2}$ in particular has been studied extensively to monitor gas leakage in diverse real time applications. The basic sensing principle behind metal oxide based thin or thick film is that there will be a change in the electrical resistance due to gas reacting with negatively charged oxygen that is adsorbed on the surface of the $\mathrm{SnO}_{2}$ nanoparticles [2-6]. Mostly metal oxide gas sensors are rugged in nature and easy to use and the performance of these metal oxide sensing mechanisms is highly dependent on the operating temperature [7-13]. They also pose poor sensitivity and selectivity when being used in a multigas environment. In order to overcome the same, doped metal oxide thin films are being used very recently. The dopant is chosen such as to either improve conductivity of the film, increase sensitivity or selectivity towards the sensing gas, or bring about better stability of the sensing layer over prolonged usage or at higher temperatures. Doping on the other hand enhances the sensing properties by changing the grain size and structure through the introduction of surface defects and impurity level. In $\mathrm{SnO}_{2}$ due to availability of the $4 \mathrm{f}$ shells it has received much attention. It is used to detect various VOCs and has shown good responses.

Various synthesis methods such as sol-gel [14-18], RF sputtering [19], electrospinning [20-23], spray pyrolysis [24, 25], vacuum evaporation [26], and hydrothermal method have been employed [27]. Among them, hydrothermal technique has been extensively used for the synthesis of $\mathrm{SnO}_{2}$. 
Hydrothermal technique is a single-step process which uses low temperature and pressure to produce high purity product and homogeneity. Tin oxide in particular is an $\mathrm{N}$-type semiconductor and it has been chosen due to its chemical, physical, and optical properties like wide energy gap, dielectric constant, and its ease of synthesis [28].

In this paper, pure and $\mathrm{Ce}$ doped $\mathrm{SnO}_{2}$ nanoparticles have been used as a sensing material for ammonia and a comparison has been made with its undoped form. The sample with pure and $\mathrm{Ce}$ doped $\mathrm{SnO}_{2}$ was also studied for its ethanol sensing ability. Ammonia $\left\{\mathrm{NH}_{3}\right\}$ is a colourless gas characterized by irritating or pungent smell. Exposure to high concentration of ammonia is a threat to human health and $50 \mathrm{ppm}$ is the lowest limit of ammonia that can be sensed by perception of smell [29]. Even below this lower limit, it causes irritation to human eyes, to skins, and even to the respiratory system. Ammonia is widely used in automotive industry, medical field, and chemical industry, so it is necessary to develop a sensor to monitor the concentration of ammonia.

In this report, $\mathrm{SnO}_{2}$ powder with $2 \% \mathrm{Ce}$ doped was prepared by hydrothermal method and the same has been coated as a thin film by spin-coating technique. It was spun at 5500 RPM for a very short duration to get a uniform thin film of the sensing material on the ITO plates. In this paper we report the comparison between the undoped and doped $\mathrm{SnO}_{2}$, thereby proving that $\mathrm{Ce}$ doped one has more sensitivity to ammonia [30-32]. Morphology and microstructure were studied by X-ray diffraction, FTIR, scanning electron microscopy, and EDX. The responses of the nanoparticles of undoped and doped were tested for ammonia vapours and ethanol gas at different temperatures and with different concentrations. Optimum operating temperatures of both $\mathrm{Ce}$ doped and undoped $\mathrm{SnO}_{2}$ were determined.

Gas sensing characteristics are determined by the material surface nature of the sensing layer to the sensed gas. Morphology of the metal oxide in terms of its size, shape, crystal faces, and dopants added to it plays a dominant role in determining the sensitivity and selectivity of the material towards the sensing gas [33-36]. Metal oxide based nanocomposites have recently been explored towards gas sensing and have been proven to have enhanced gas sensing abilities even at room temperature $[37,38]$.

Ammonia being a most useful industrial gas is used in various processes and manufacturing industries. It has also evolved as a harmful byproduct in various chemical oriented industries. An overview on need for ammonia sensing and various ammonia sensing mechanisms has already been reviewed [39]. Pure $\mathrm{SnO}_{2}$ [40] and doped $\mathrm{SnO}_{2}[33,41]$ based gas sensors have been reported to sense ammonia gas with good efficiency. Newer mechanisms to synthesize gas sensing nanomaterials such as surfactant assisted facial hydrothermal process have been reported which could be used to sense ammonia even at low temperatures [42].

Many other metal oxides like indium oxide have been studied for their gas sensing abilities towards sensing ammonia and ethanol $[9,36,43]$. The sensors provided less sensitivity than $\mathrm{SnO}_{2}$. Other materials like polyaniline [44] and high-order aluminium nanoporous structures [45] have been explored towards sensing ammonia and even humidity. Several gas sensors were also developed to selectively sense ammonia in the exhaust gas $[46,47]$. Various zeolites and metal oxide frameworks also have been studied and applied for gas sensing applications such as automotive gas analysis [47, 48]. This technique helps in synthesizing a particular crystalline structure of metal oxide nanomaterials. Some sensors were tried by sensing ammonia based on in-plane impedance metric technique using semiconductor enhanced CNTs [49]. Apart from gas sensing metal oxides based nanocomposites have been effectively used for various applications like enhanced visible light-driven photocatalyst and supercapacitor electrodes [50]. An interesting work on sensing $\mathrm{NO}_{2}$ using physisorption on tin disulfide based $2 \mathrm{D}$ nanostructures has been reported [51]. This technique has showcased excellent selectivity towards $\mathrm{NO}_{2}$ at lower operating temperatures when exposed even at lower concentrations.

\section{Materials and Methods}

2.1. Chemicals. Tin(IV) chloride pentahydrate $\left(\mathrm{SnCl}_{4} \cdot 5 \mathrm{H}_{2} \mathrm{O}\right)$ (98\% pure), cerium nitrate $\mathrm{Ce}\left(\mathrm{NO}_{3}\right)_{3} \cdot 6 \mathrm{H}_{2} \mathrm{O}$, ammonia, and ethanol solution were procured from Sigma Aldrich. All chemicals were of analytical grade and are used without any further purification.

2.2. Synthesis of Ce Doped $\mathrm{SnO}_{2}$ Nanoparticles. Hydrothermal technique was employed for the synthesis of Ce doped $\mathrm{SnO}_{2}$ nanoparticles. Tin(IV) chloride pentahydrate was used as the precursor. $7.5 \mathrm{mM}$ of $\mathrm{SnCl}_{4} \cdot 5 \mathrm{H}_{2} \mathrm{O}$ was dissolved in $75 \mathrm{~mL}$ of ethanol and stirred vigorously. The solution was added with $2.15 \mathrm{mM}$ of cerium nitrate and stirred further for 30 minutes. The quantity of cerium salt added to the precursor is the determinant factor which decides the wt $\%$ of $\mathrm{Ce}$ doped in $\mathrm{SnO}_{2}$. The wt\% of cerium can be easily changed with this quantity. In this process the $2.15 \mathrm{mM}$ of cerium nitrate corresponds to $2 \mathrm{wt} \%$ of $\mathrm{Ce}$ in $\mathrm{SnO}_{2}$. After stirring for a duration of 15 minutes the solution was transferred to Teflon lined stainless steel autoclave. The solution in the autoclave was heated to a temperature of $180^{\circ} \mathrm{C}$ in a hot air oven and maintained at the same temperature for twenty hours. After heating is complete, the autoclave was air-cooled till it reached the room temperature. The derived solution was centrifuged, washed, and decanted with distilled water three times. Finally the solution was washed with ethanol. The sample was kept for drying at $80^{\circ} \mathrm{C}$ in hot air oven for eight hours to remove ethanol residues from the sample and to provide thermal stability to the material.

2.3. Gas Sensing Chamber Specifications and Sensing Methodology. Gas sensing was carried out in air tight temperature controlled chamber (Scheme 1). The gas sensing chamber was designed to be operated based on flow metric principle. The gas chamber was novel and unique when compared to traditionally used volumetric gas sensing chambers. Volumetric gas sensing chambers typically require huge sample gas volumes ranging up to few litres of sample gas in many cases. Moreover they work on gravimetric principle. The 


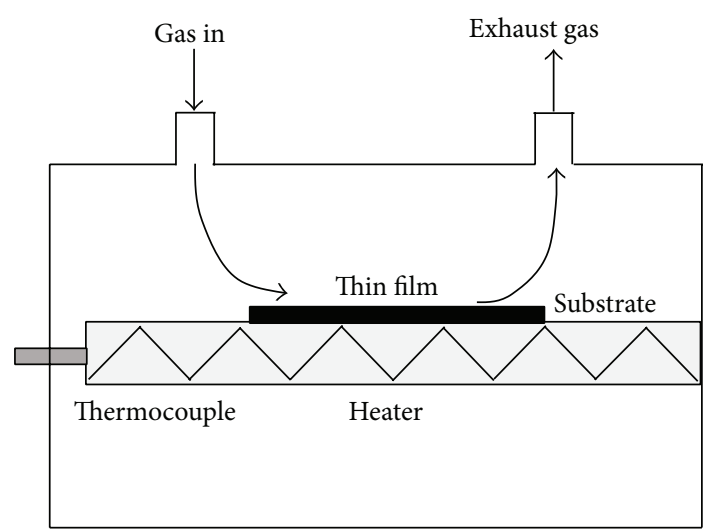

Scheme 1: A schematic of the designed gas sensing chamber.

gas sensor is placed at the bottom of the chamber and the exposed gas needs to reach the sensor to react and provide a response. The heat spread in the chamber also is not uniform creating a highly thermodynamic environment in the chamber. The heat rise and fall gradients would require large response time intervals, resulting in larger sample analyses time duration. All these demerits can be eliminated using the proposed chamber. The chamber was designed using COMSOL Multiphysics, a FEM based design, simulation, and analysis software. The chamber design was optimized for various parameters such as characteristic flow length inside the chamber, optimal placement of the substrate holder, substrate holder dimensions, heater performance, and conductive heat transfer from the heater to the surface of the thin film through the substrate holder and substrate. The flow characteristics inside the chamber were carefully studied in optimizing the above-mentioned parameters.

The finalised design was manufactured by outsourcing from a professional gas chamber manufacturer. The manufactured gas sensing chamber was tested for the flow characteristics, heat transfer, and temperature stability requirements. The practical results were within satisfactory tolerance limits as compared with the software based analysis. The chamber was made of stainless steel and was in cylindrical in shape provided with $\mathrm{O}$ rings and good vacuum sealing arrangements. The chamber was designed with highly efficient heater along with thermocouple based closed loop feedback given to an electronic circuit with PID controller for the temperature control. The heater consisted of a nichrome heating element encased inside a steel protective sheath. The steel encasing is of benefit in providing very good heat transfer abilities along with good structural stability. The heater was designed with the substrate holder to support thin film as well as cylindrical coated substrates. The substrate holder was designed to be part of the heater, thus ensuring good heat transfer from heater to the substrate coated with reactive thin film. A thermocouple placed in contact with the substrate holder gives a closed loop feedback to the temperature control circuitry, thus enabling dynamic and optimized control of substrate temperature. A J type thermocouple (Iron-Constantan) is

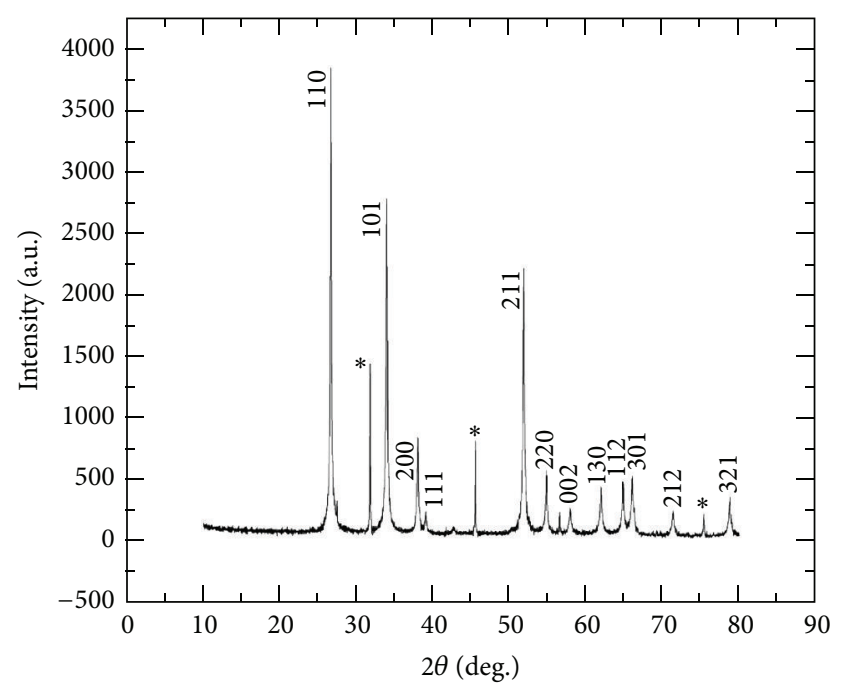

FIgURE 1: XRD of the Ce doped $\mathrm{SnO}_{2}$ thin film with signature Ce peaks.

used in the experiment as it can be used in reducing atmosphere. A constant relationship is maintained with the help of the PID controller, hence controlling the current allowed to flow through the heater thereby controlling the temperature of the heater. The electrical contacts are established onto the thin film by means of thin silver wire bonded to the film using silver conductive paste.

The thin films were made by spin coating the synthesized material on ITO films with nafion being used as binder. The coated films were placed onto the substrate holder and heated to the desired temperature. Gas was allowed to flow into the chamber through the inlet port of the chamber. The substrate holder was optimally placed to achieve laminar flow over the gas sensor. The gas sensing occurs due to the chemisorption occurring between the analyte gas and the surface atoms of the sensing material. This results in the change in the resistance of the thin film sensor which is measured using a highly accurate Agilent multimeter. The exhaust gas is vented out of the chamber through the exhaust port of the chamber.

\section{Results and Discussion}

3.1. Structural Properties and Morphological Analysis. The $\mathrm{XRD}$ pattern of the Ce doped $\mathrm{SnO}_{2}$ is shown in Figure 1. The XRD pattern of the undoped $\mathrm{SnO}_{2}$ showed distinctive peaks at $26.67^{\circ}, 33.95^{\circ}, 37.95^{\circ}, 38.97^{\circ}, 51.75^{\circ}, 54.76^{\circ}$, and $65.96^{\circ}$, which correspond to (110), (101), (200), (111), (211), (220), (002), and (321) planes of the $\mathrm{SnO}_{2}$. This data is in well agreement with the JCPDS data (JCPDS File number 411445). The crystalline structure of the synthesized material was tetragonal rutile based on the JCPDS reference data. Ce doped XRD patterns look very similar to the pure $\mathrm{SnO}_{2}$ with crystalline structure of $\mathrm{SnO}_{2}$. Signature peaks of $\mathrm{Ce}(*)$ are present at $31.82^{\circ}, 46.28^{\circ}$, and $75.34^{\circ}$ which matches JCPDS data (JCPDS File number 001-0745) and $\mathrm{CeO}_{2}$ is present at 


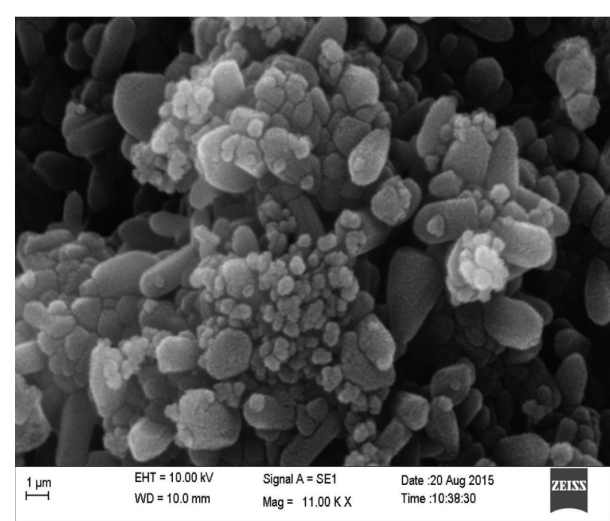

(a)

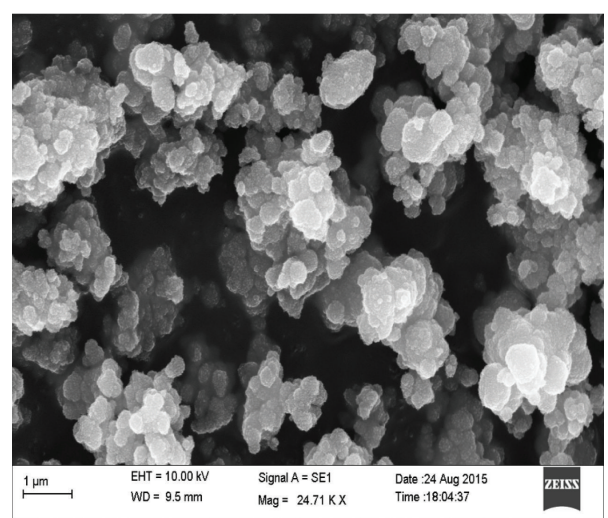

(c)

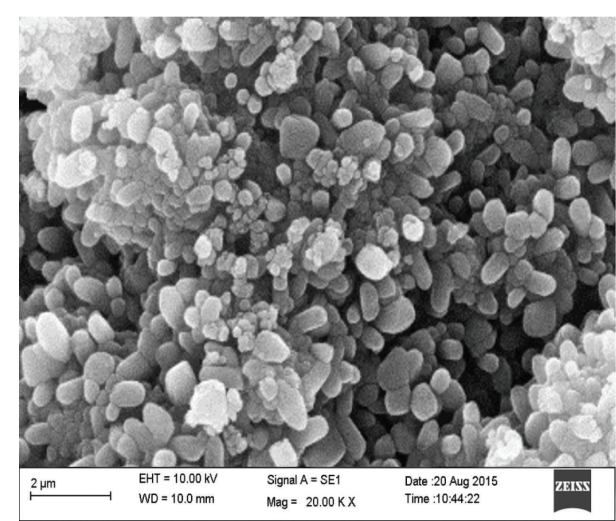

(b)

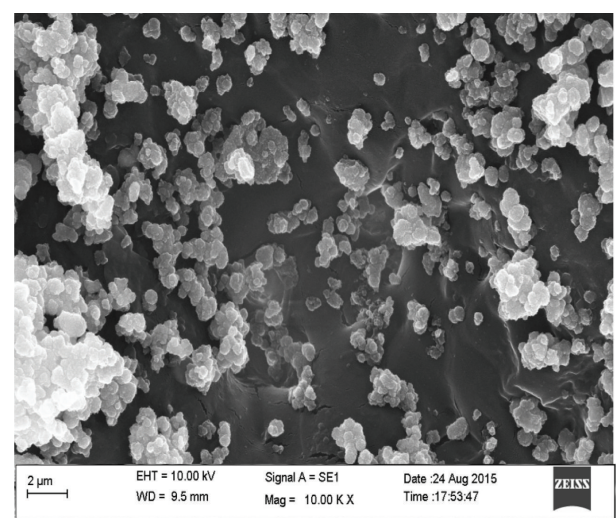

(d)

Figure 2: Undoped $\mathrm{SnO}_{2}$ nanoparticles (a) and (b). Ce doped $\mathrm{SnO}_{2}$ nanoparticles (c) and (d).

$76.81^{\circ}$ which matches JCPDS data (JCPDS File number 0010800). Upon calcination at $180^{\circ} \mathrm{C}$ for 2 hours, these peaks are suppressed.

The cassiterite phase can be found with clear proof of the dopant. Even though, it is well known that with $\mathrm{Ce}^{4+}$ atoms being slightly larger in size when compared to $\mathrm{Sn}^{4+}$, there is a higher possibility for substitution of Sn ions with Ce ions without disrupting the cassiterite phase structure. It is also possible that separated phase of Ce can exist on the surface lattice of $\mathrm{SnO}_{2}$ nanoparticles which might lead to forming distinctive peaks at $\mathrm{Ce}$ characteristic wavelengths. The size of the particles was calculated using Scherer's formula from the XRD data [33]:

$$
D=\frac{0.89 \lambda}{(\beta \cos \theta)},
$$

where $D$ represents the particle size, $\theta$ is the Bragg angle, $\beta$ is the full width at half maxima, and $\lambda$ is the wavelength of the X-ray used (1.541876 $\AA$ ). The size of the undoped $\mathrm{SnO}_{2}$ nanoparticles was calculated to be of $24 \mathrm{~nm}$ of size. The size of the Ce doped $\mathrm{SnO}_{2}$ nanoparticles was calculated to be of $28 \mathrm{~nm}$ of size.

The SEM images for both undoped and $\mathrm{Ce}$ doped $\mathrm{SnO}_{2}$ are shown in Figure 2. The undoped $\mathrm{SnO}_{2}$ nanoparticles are cone shaped with an average diameter of $51 \mathrm{~nm}$. The nanoparticles were found to be with larger distribution of particles. Introduction of Ce dopant resulted in larger sphere shaped structures with a repetitive arrangement. The Ce doped $\mathrm{SnO}_{2}$ nanoparticles have an average diameter of size of $61 \mathrm{~nm}$. Further increasing the dopant, the nanoparticles resulted in the formation of larger spheres because, with the addition of cerium ions, the crystallite size decreases, thereby resulting in agglomeration of particles.

The EDX analysis was performed along with SEM for both undoped and $\mathrm{Ce}$ doped $\mathrm{SnO}_{2}$ nanoparticles. The EDX spectrum of undoped $\mathrm{SnO}_{2}$ sample shown in Figure 3 revealed the dominant presence of $\mathrm{Sn}$ and O. The EDX spectrum of the Ce doped $\mathrm{SnO}_{2}$ sample shown in Figure 4 depicts the presence $\mathrm{Ce}$ in smaller percentage when compared with $\mathrm{Sn}$ and O. The analysis revealed that the chemical composition of the synthesized particles with weight percentage of the cerium is around $2.29 \%$ compared to that of $\mathrm{Sn}$ and $\mathrm{O}$ in case of $\mathrm{Ce}$ doped $\mathrm{SnO}_{2}$. This confirms that $2 \mathrm{wt} \%$ of $\mathrm{Ce}$ was doped onto the $\mathrm{SnO}_{2}$ nanomaterial as per the synthesis procedure illustrated earlier. The EDX spectrum also confirms the chemical composition for both undoped and Ce doped $\mathrm{SnO}_{2}$ nanoparticles. It is clearly evident that Sn being a dominant element has a higher wt $\%$ ratio when compared to $\mathrm{O}$ or Ce. Certain distinctive peaks can be observed for Ce which illustrates the Ce presence at lower levels in the Ce doped $\mathrm{SnO}_{2}$ nanocomposite. 


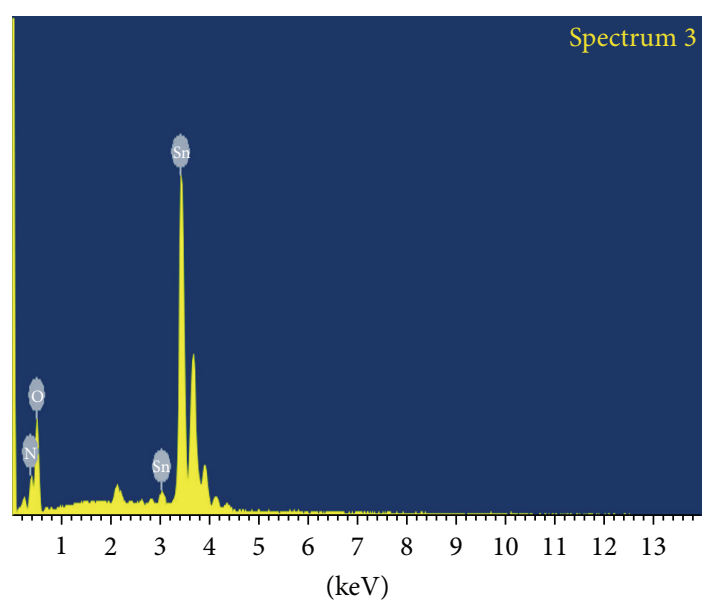

Full-scale 3257 cts cursor: 0.000

FIgURE 3: EDX analysis of undoped $\mathrm{SnO}_{2}$.

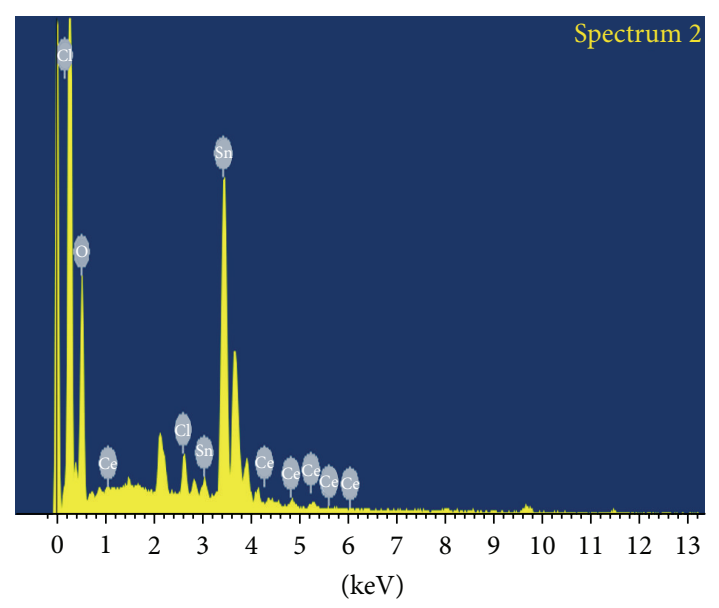

Full-scale 3206 cts cursor: 0.000

FIgure 4: EDX analysis of Ce doped $\mathrm{SnO}_{2}$.

3.2. FTIR Analysis. FTIR analysis was performed on the synthesized nanomaterial to identify the chemical elements present in the sample. Ce doped $\mathrm{SnO}_{2}$ nanoparticles were characterized by FTIR spectroscopy at room temperature in the range of 450 to $4000 \mathrm{~cm}^{-1}$. Various well-defined peaks of Ce dopant were observed from Figure 5 at 511, 800, $1400.32,1632$, and $3420 \mathrm{~cm}^{-1}$. FTIR spectral analysis of Ce doped $\mathrm{SnO}_{2}$ shows the absorption band at $3400 \mathrm{~cm}^{-1}$ corresponding to Sn-OH group. A prominent peak at $632 \mathrm{~cm}^{-1}$ is due to the antisymmetric Sn-O-Sn stretching mode of the surface bridging oxide formed due to the condensation of adjacent surface hydroxyl group's vibrations [17]. This peak confirms that the $\mathrm{SnO}_{2}$ nanomaterial had been successfully synthesized. Furthermore the peaks around $1631 \mathrm{~cm}^{-1}$ and $3213 \mathrm{~cm}^{-1}$ show the bending vibration of absorbed water and stretching vibration of $-\mathrm{OH}$.

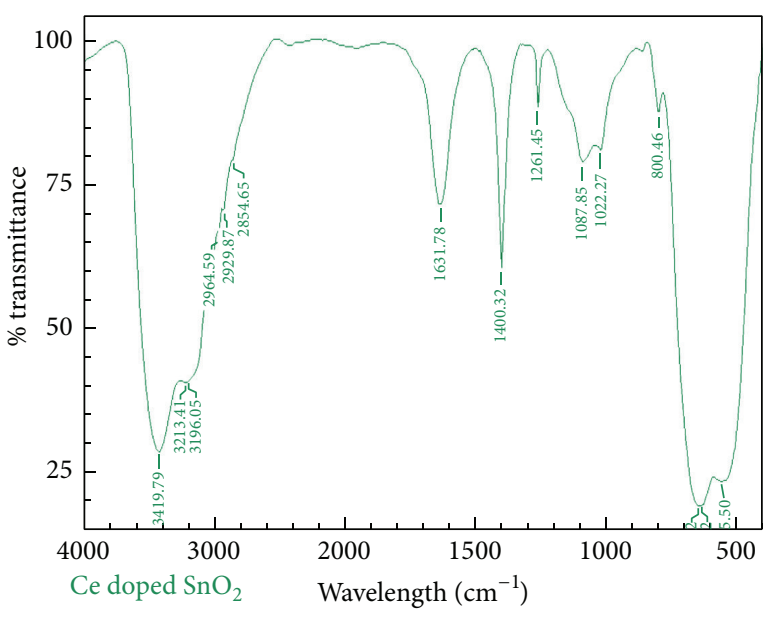

FIgURE 5: FTIR analysis of Ce doped $\mathrm{SnO}_{2}$.

\section{Gas Sensing Process Description}

This work involves synthesizing $\mathrm{SnO}_{2}$ nanomaterials with and without $\mathrm{Ce}$ doping and studies its gas sensing properties towards ammonia. A special gas sensing chamber was designed uniquely for this requirement. The synthesized nanoparticles were made into a gel with nafion as binder and the gel was spin-coated onto an ITO plate at 5500 RPM. The coated ITO plate was then air-dried in hot air oven at $120^{\circ} \mathrm{C}$ for one hour which evaporated the nafion and resulted in a $\mathrm{SnO}_{2}$ thin film coated ITO plate. The resistance of the thin film was measured using Agilent multimeter. The coated thin film was placed on the substrate holder and kept in the gas sensing chamber. The substrate holder was attached to a heater whose temperature can be controlled using thermocouple based feedback. The substrate was heated to a particular temperature. After the substrate had attained a stabilized temperature, the chamber was flushed with nitrogen gas. The resistance of the thin film was again measured without any gas flowing through it at elevated temperature. Then the preheated ammonia was pumped into the gas sensing chamber at various flow rates using a peristaltic pump. The gas was allowed to flow over the heated substrate resulting in a chemisorption on the coated thin film surface due to affinity between the gas and the coated reactive thin film. This process results in the change in the resistance of the thin film. The stabilized values of the resistance of the thin film at different flow rates were measured for different flow rates of the gas and were analysed for the gas sensing properties of the thin film. The resistance change was attributed to the change in ammonia gas concentration and flow rate. With the flow rate kept constant the concentration of the gas could be derived based on resistance of the thin film.

\section{Measurements and Sensing Performance}

5.1. Temperature Dependent Resistance Studies. The gas sensing response of the thin film was observed as a resistance change of the film as the coated nanomaterial reacted with the exposed gas. The resistance measurement was done using 


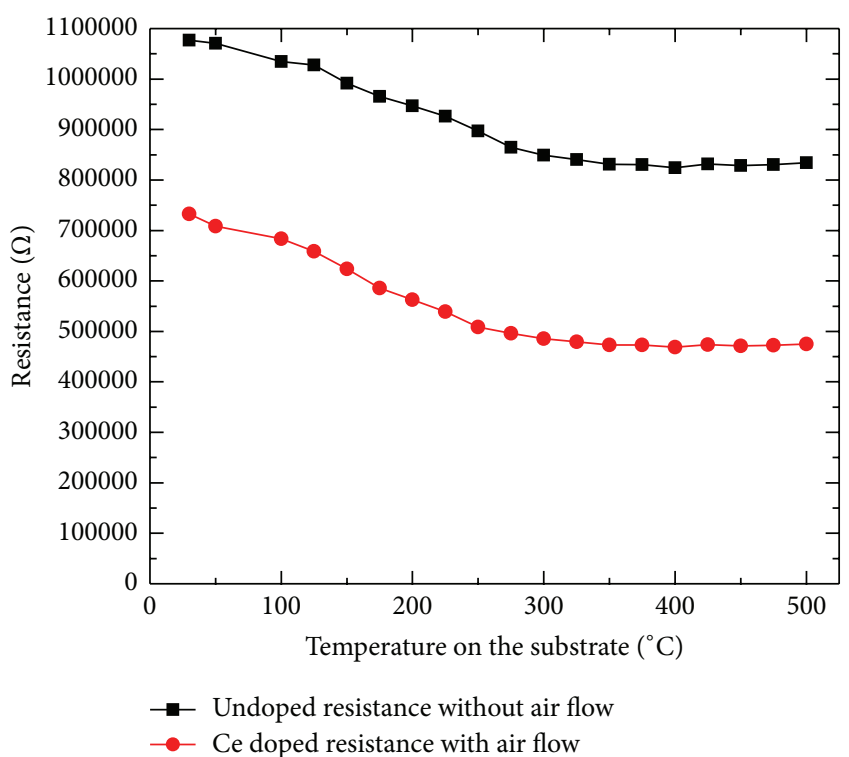

Figure 6: Temperature dependence of the undoped $\mathrm{SnO}_{2}$ and Ce doped $\mathrm{SnO}_{2}$ thin films.

Agilent digital multimeter (Model 34401A). The initial resistance of the material was recorded at ambient conditions. The sensor response was recorded with increment in substrate temperature with no air (or) gas passing through it. This would be helpful to calibrate the sensor response to remove the temperature dependent resistance variation errors.

Metal oxide gas sensors showcase their gas sensing response in terms of resistance change with the change in the concentration of the gas being sensed. Metal oxide gas sensors exhibit their maximum sensitivity at elevated temperatures. Their surface activity increases with the temperature and attains a maximum value at an optimum operating temperature. The resistance change of the thin film formed with temperature variation is critical for validating the sensors response. The resistance of the sensor is recorded for both doped and undoped films at various temperatures as depicted in Figure 6.

5.2. Gas Exposure Studies on Undoped $\mathrm{SnO}_{2}$ Thin Film Sensor. The response of the sensing film was studied with and without the air flow over the substrate. It was observed that both undoped and $\mathrm{Ce}$ doped $\mathrm{SnO}_{2}$ thin films showed a reasonable decrease in their film resistance with increase in temperature even without air flowing over them. The resistance change pattern for both films was similar to that without air flow but with lower resistance values. The resistance change was almost negligible at higher temperatures due to saturation. Ce doped $\mathrm{SnO}_{2}$ film showed a comparatively higher change in the resistance than the undoped film in both cases as shown in Figure 7. Moreover it was also observed that the doped film had a comparatively lower initial resistance than the undoped film. This data could be analysed to determine the optimal working temperature of the sensor too. It could be inferred from the resistance versus temperature graph that the thin film exhibited a maximum change in resistance at $300^{\circ} \mathrm{C}$ for

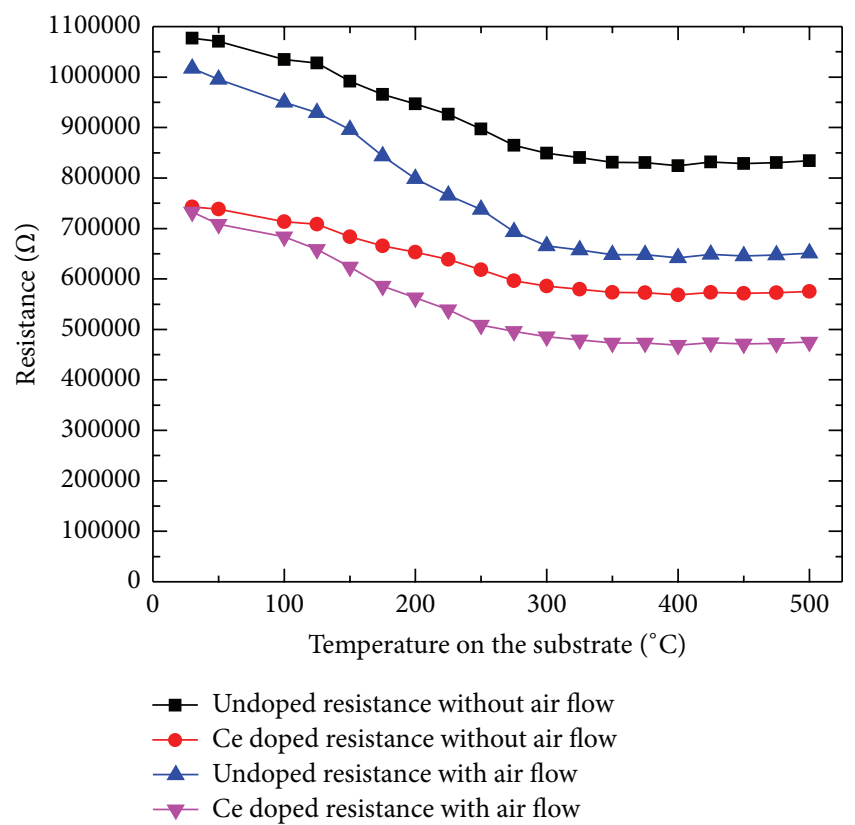

FIGURE 7: Temperature dependent resistance change of the Ce doped and undoped $\mathrm{SnO}_{2}$ thin film with and without air flow.

Ce doped $\mathrm{SnO}_{2}$ thin film. After the temperature got stabilized the film was exposed to ammonia vapour. The change in the resistance of the sensor was observed and is recorded after the resistance stabilized to a constant value.

It is highly essential to establish the optimum operating temperature at which the sensor would be able to sense a given gas with maximum sensitivity. In order to determine this optimum temperature, both undoped and doped films were exposed to $500 \mathrm{ppm}$ of gas flowing through the chamber at a constant flow rate of $10 \mathrm{~mL} / \mathrm{min}$. The resistance of the sensor was observed at room temperature and from there on with increments of $25^{\circ} \mathrm{C}$ for every observation. The resistances were found to be decreasing gradually with the increase in temperature. The sensor response was observed to be having lowest resistance at $425^{\circ} \mathrm{C}$ while sensing ammonia and $400^{\circ} \mathrm{C}$ while sensing ethanol. It was also observed that the film response starts increasing with the increase in the temperature. After the optimum temperature the resistance of the film was observed to increase with increase in temperature as shown in Figure 8. This behaviour in sensor response was reported in various metal oxide systems while sensing various gases [24, 29].

Sensitivity is defined as the ratio between differential response between gas flow and air flow to the resistance of the sensing film when exposed to air:

$$
\text { Sensitivity }=\left(\frac{R_{a}-R_{g}}{R_{a}}\right) * 100 \% \text {, }
$$

where $R_{a}$ is the resistance of the sensor when exposed to air and $R_{g}$ is the resistance of the sensor when exposed to the corresponding gas at the same temperature.

The sensitivity of the sensor in Figure 9 also showcased the same information as the resistance change plot. The 


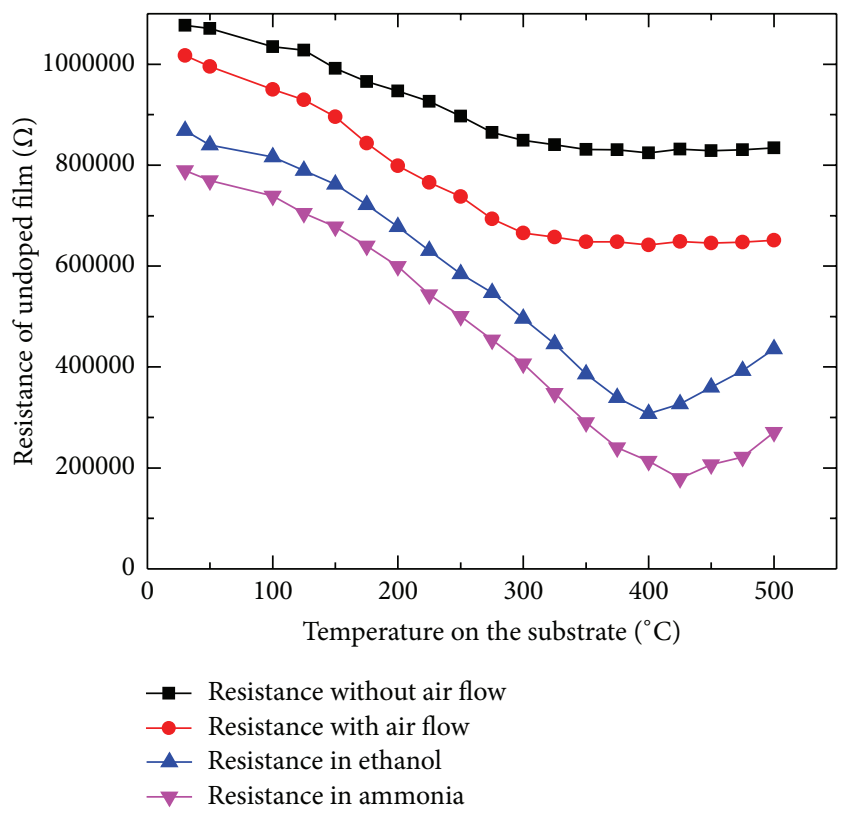

FIGURE 8: Resistance of sensing film towards ammonia and ethanol with increase in the temperature of undoped $\mathrm{SnO}_{2}$ thin film.

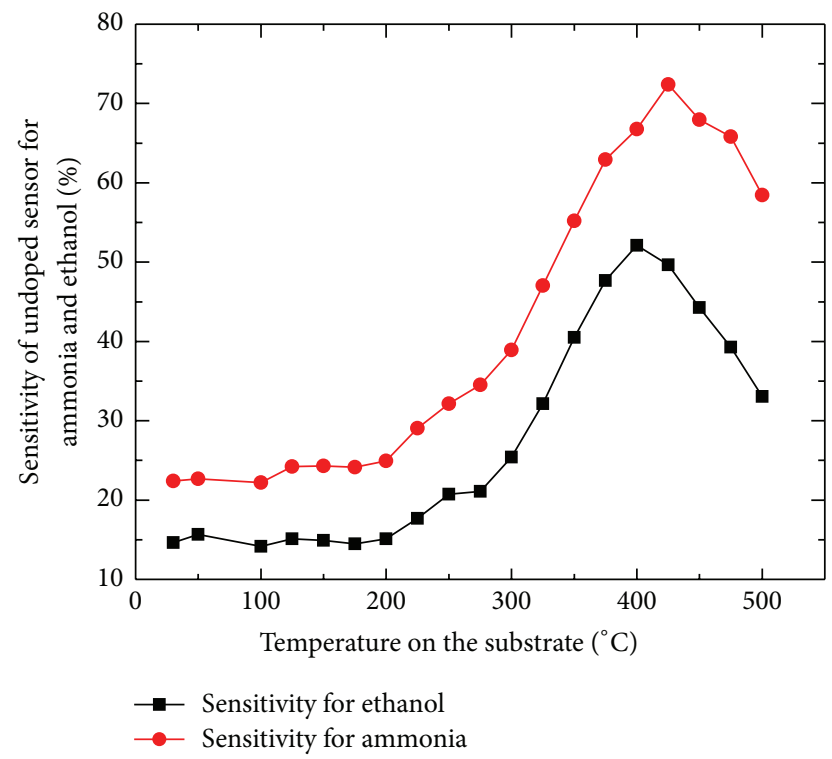

FIGURE 9: Sensitivity of undoped sensing film towards ammonia and ethanol as a function of temperature.

sensitivity of the sensor was found to be increasing with the increase in temperature. A maximum of sensitivity of $72 \%$ was observed while sensing ammonia at a temperature of $425^{\circ} \mathrm{C}$. The sensitivity decreased from the maximum value above and below this temperature which can be considered as the optimum operating temperature of the sensor towards sensing ammonia. The undoped sensor was observed to provide a maximum sensitivity of only $52 \%$ at a slightly lower temperature of $400^{\circ} \mathrm{C}$. The sensor showed a better selectivity towards ammonia, but the responses between ammonia and

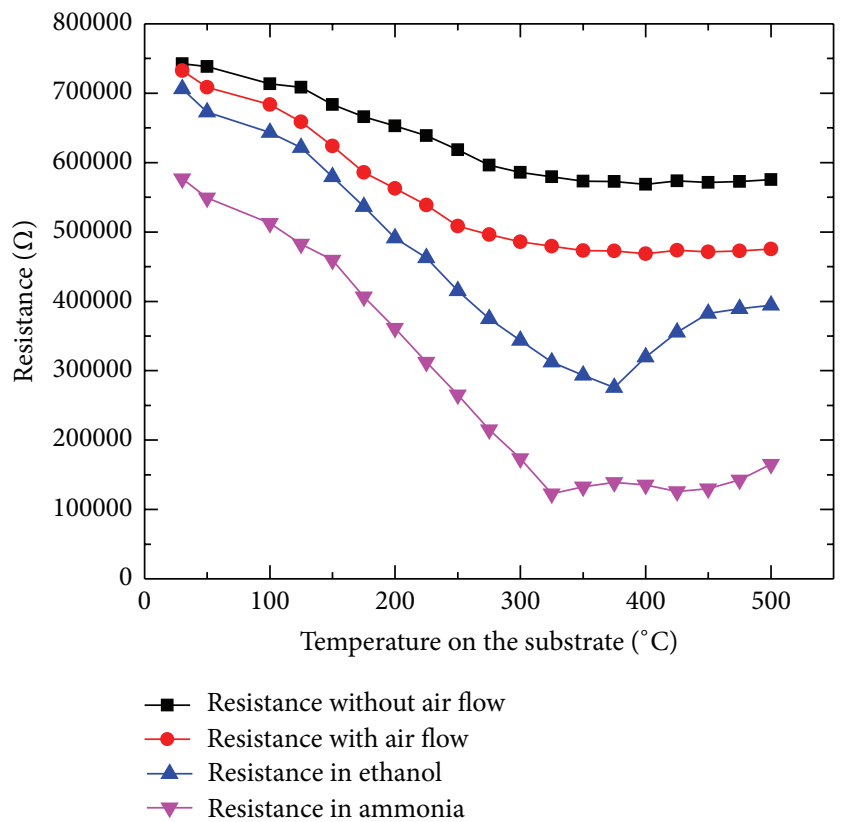

FIGURE 10: Resistance of sensing film towards ammonia and ethanol with increase in the temperature of Ce doped $\mathrm{SnO}_{2}$ thin film.

ethanol were not appreciably distinctive response as their operating temperatures were pretty closer. The responses also were identical with a slightly higher sensitivity towards ammonia when compared to ethanol at all temperatures as plotted in Figure 9.

5.3. Gas Exposure Studies on Ce Doped $\mathrm{SnO}_{2}$ Thin Film Sensor. The tests performed on pure $\mathrm{SnO}_{2}$ thin film sensor were also conducted on the Ce doped $\mathrm{SnO}_{2}$ thin film sensor. The first test was carried out with measuring resistance change with temperature variation with no air flow over the sensor. The initial test of measuring resistance when exposed to air helps to observe the baseline response of the sensor which would be taken as reference for determining the sensitivity. It would also help to sensitize the sensing film to high temperatures before exposure to the sensing gas. The thermal stability of the sensor would be improved with the initial air exposure. It was observed that the Ce doped thin film exhibited lesser resistance when compared to the undoped pure $\mathrm{SnO}_{2}$ thin film sensor. The resistance, as showcased in Figure 10, decreased gradually with increase in temperature. The temperature change got saturated around $300^{\circ} \mathrm{C}$. The same sensor was tested with airflow at a constant flow rate of $10 \mathrm{~mL} / \mathrm{min}$. The initial resistance was slightly lesser than the previous test. The resistance decreased with marginally increased factor compared to no-air flow condition. Then the actual gas exposure testing was performed on the sensor. The sensor was exposed to $500 \mathrm{ppm}$ of ethanol at a constant flow rate of $10 \mathrm{~mL} / \mathrm{min}$ into the chamber. The resistance change of the sensor was recorded with the increase in temperature at increments of $25^{\circ} \mathrm{C}$. The sensor response was allowed to settle down to almost a constant value of resistance, thereby ensuring that stable reading was recorded. 


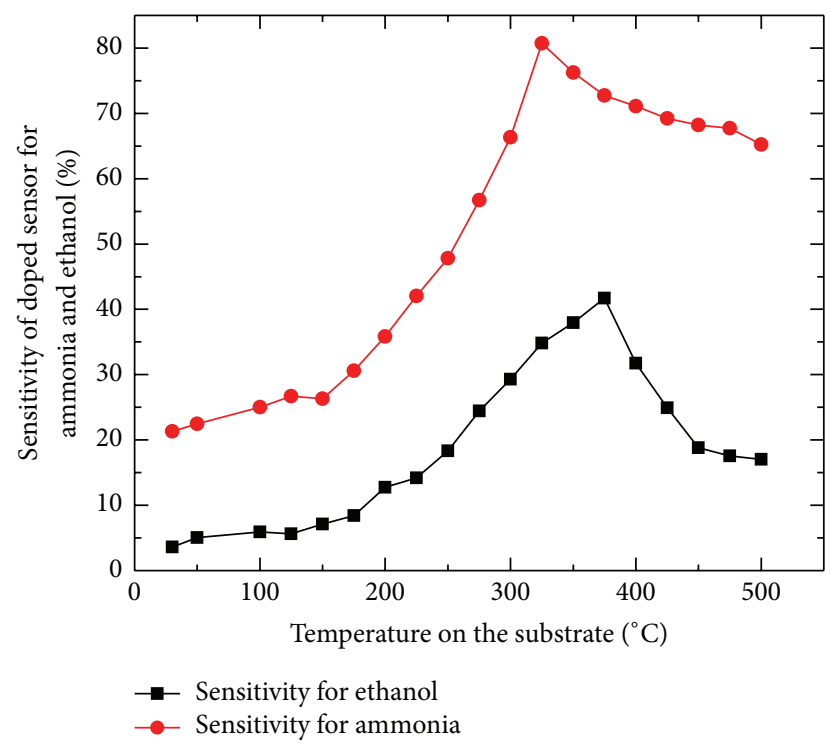

FIGURE 11: Sensitivity of sensing film towards ammonia and ethanol as a function of temperature of $\mathrm{Ce}$ doped $\mathrm{SnO}_{2}$ thin film.

It was observed that the resistance dropped with a significant change when compared to air. This is due to the chemical reaction between the oxygen adsorbed onto the surface of the sensor and the exposed gas. The resistance change maxed at a temperature of $375^{\circ} \mathrm{C}$. Beyond that temperature, the resistance increased gradually. When the sensor was exposed to ammonia, there was a considerable change in the resistance even at room temperature. The resistance of the sensor decreased very significantly with the change in temperature. The maximum change in resistance when compared with initial value was observed at $325^{\circ} \mathrm{C}$. The resistance slightly increased with increase in temperature beyond $325^{\circ} \mathrm{C}$.

It can be judged from the response plotted in Figure 11 that the optimum temperature to sense ammonia using this Ce doped $\mathrm{SnO}_{2}$ thin film sensor would be $325^{\circ} \mathrm{C}$ and to sense ethanol using the same sensor would be at a lower temperature of $375^{\circ} \mathrm{C}$. In both cases of sensing ammonia and ethanol, it is evident that the Ce doped $\mathrm{SnO}_{2}$ thin film sensor exhibited better resistance change towards the same concentration of exposed gas at a much lower optimum operating temperature when compared to that of undoped pure $\mathrm{SnO}_{2}$ thin film sensor. The lower operating temperature of the Ce doped $\mathrm{SnO}_{2}$ can be attributed to reduction in the band gap of the $\mathrm{SnO}_{2}$ nanomaterial [35]. The doping of Ce with higher electron mobility than Sn would be a favourite dopant for gas sensing applications. The sensitivity of the $\mathrm{Ce}$ doped sensing $\mathrm{SnO}_{2}$ towards ethanol and ammonia was also determined by relating the differential response between gas flow and air flow. This would help to determine the change in resistance towards constant flow of air and to that of the corresponding gas flow at the same gas flow rate. The sensitivity plot of the sensor exhibited that the Ce doped $\mathrm{SnO}_{2}$ thin film sensor had a much higher sensitivity of $76 \%$ towards sensing ammonia at a much lower operating temperature of $325^{\circ} \mathrm{C}$. The sensor had a lesser maximum sensitivity of $41 \%$

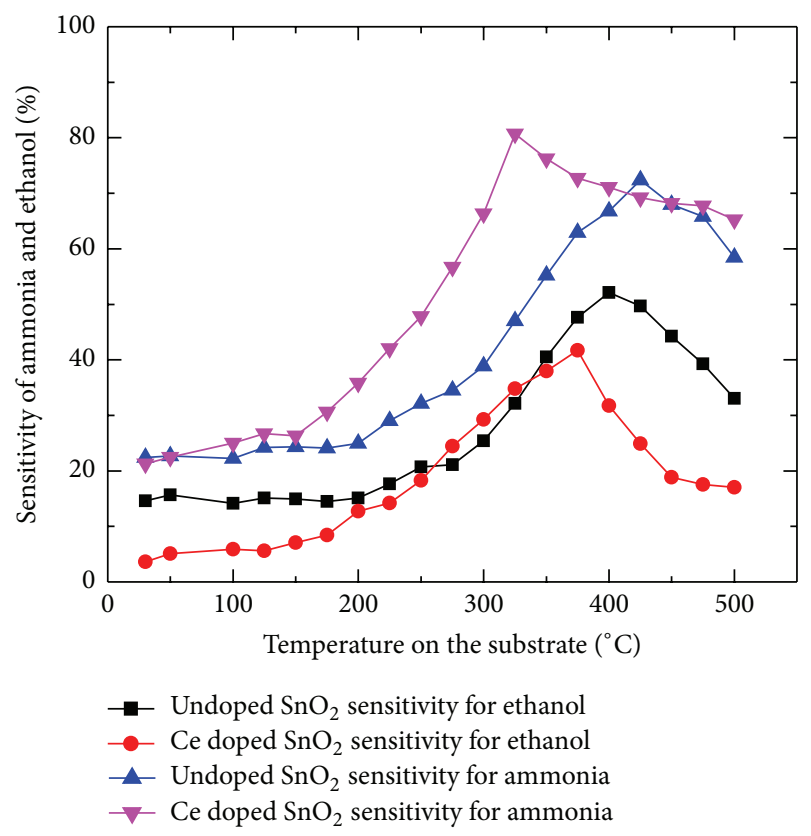

Figure 12: Sensitivity of Ce doped and undoped $\mathrm{SnO}_{2}$ sensing film towards ammonia and ethanol as a function of temperature.

at an operating temperature of $375^{\circ} \mathrm{C}$. Again the Ce doped $\mathrm{SnO}_{2}$ thin film sensor showed a significantly dominating selectivity towards ammonia when compared to ethanol like the undoped $\mathrm{SnO}_{2}$ thin film sensor.

A comparative analysis of sensitivities of undoped and $\mathrm{Ce}$ doped $\mathrm{SnO}_{2}$ thin films towards sensing ammonia and ethanol can be viewed from Figure 12. It is clearly evident that the Ce doped $\mathrm{SnO}_{2}$ is a very good candidate to sense ammonia with slightly higher sensitivity than undoped $\mathrm{SnO}_{2}$, also at much lower optimum operating temperature. The doped sensor also showed a very good selectivity towards ammonia than ethanol. The doped and undoped $\mathrm{SnO}_{2}$ films did not exhibit significant change in sensitivity towards ethanol. In fact undoped $\mathrm{SnO}_{2}$ sensor was observed to have a higher sensitivity of $52 \%$ than its doped counterpart with a sensitivity of $41 \%$ but a reasonably higher operating temperature of $400^{\circ} \mathrm{C}$ when compared to that of $375^{\circ} \mathrm{C}$.

The Ce doped and undoped $\mathrm{SnO}_{2}$ sensors were exposed to varying concentrations (50 to $500 \mathrm{ppm}$ ) of ammonia and ethanol gas at their optimal operating temperatures and their responses were depicted in Figure 13. The gas sensing chamber is ensured that all the valves are leakproof to avoid leak of ammonia into the sensing environment. Moreover the exhaust gas was stored in a separate cylinder using a pump. The pump also ensures optimal constant flow of gas through the sensor at all times. The tests were performed in steps of $50 \mathrm{ppm}$ increment in the concentration of the gases. Lower increments could not be taken due to various operating constraints. The response was recorded after the reading got stabilized within $2 \%$ of fluctuation in the readings. Ce doped $\mathrm{SnO}_{2}$ film exhibited maximum sensitivity of $81 \%$ towards ammonia and undoped $\mathrm{SnO}_{2}$ exhibited maximum sensitivity of just $58 \%$ towards ammonia at $325^{\circ} \mathrm{C}$. Ce doped $\mathrm{SnO}_{2}$ film 


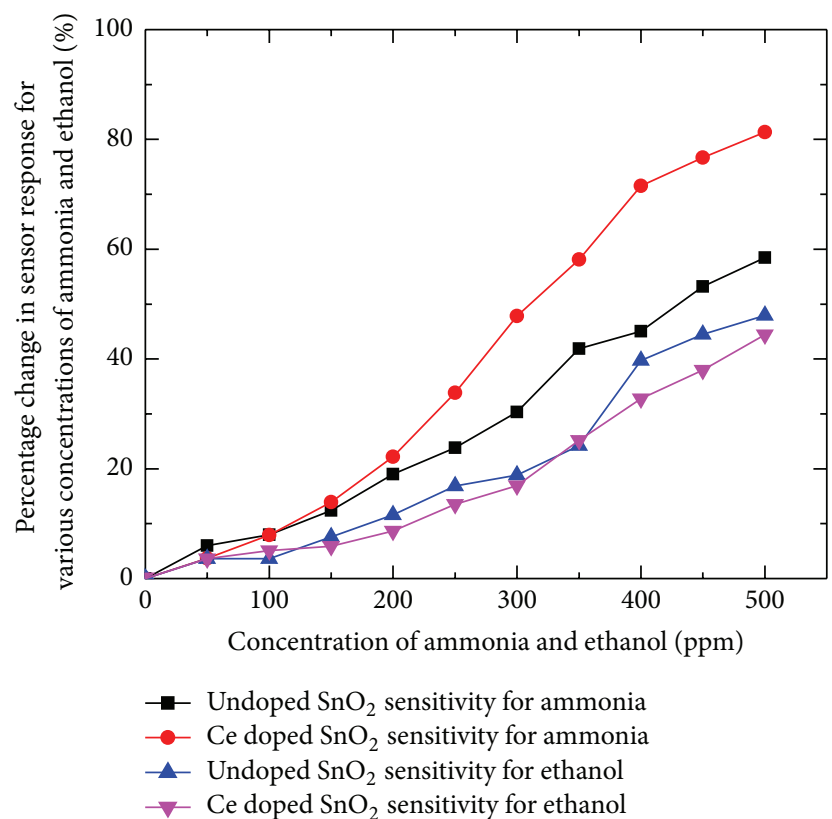

FIGURE 13: Sensitivity of Ce doped and undoped $\mathrm{SnO}_{2}$ sensing film for various concentrations of ammonia at $325^{\circ} \mathrm{C}$ and ethanol at $375^{\circ} \mathrm{C}$.

exhibited maximum sensitivity of $44 \%$ towards ammonia and undoped $\mathrm{SnO}_{2}$ exhibited maximum sensitivity of $47 \%$ towards ammonia at $375^{\circ} \mathrm{C}$. The sensor response was allowed to stabilize to a constant value for each increment of the gas concentration. It was not advisable to measure ammonia in excess of $500 \mathrm{ppm}$ owing to exposure hazards posed by ammonia on the researchers.

5.4. Response Time Analysis. Apart from observing the sensing abilities of the doped and undoped films, another important factor to study in sensors performance would be its response time characteristics. The sensor was exposed to the gas of $500 \mathrm{ppm}$ concentration at a constant flow rate of $10 \mathrm{~mL} / \mathrm{min}$ at its optimum operating temperature. The sensor response was allowed to settle down to a constant value. The time taken for the sensor to reach a constant response from the time of flow initiation is the response time of the sensor. The Ce doped $\mathrm{SnO}_{2}$ film required a response time of around 5 mins to attain a stable state. The sensor response was recorded for an extended time period of 5 more mins to confirm that the response had stabilized as showcased in Figure 14. Then the gas flow was reduced at decrements of $1 \mathrm{~mL} / \mathrm{min}$. The sensor response was observed to gradually decrease along with the decrease in gas flow. After around 11 mins the sensor had reached the initial response as it was before the gas exposure. The test was repeated again to validate the response time behaviour. The response time and pattern were found to be identical except for a slight increment in sensitivity in the second cycle due to residual gas affecting the response.

The same study was conducted on the Ce doped $\mathrm{SnO}_{2}$ with the exposure of ethanol. It was observed that the sensor

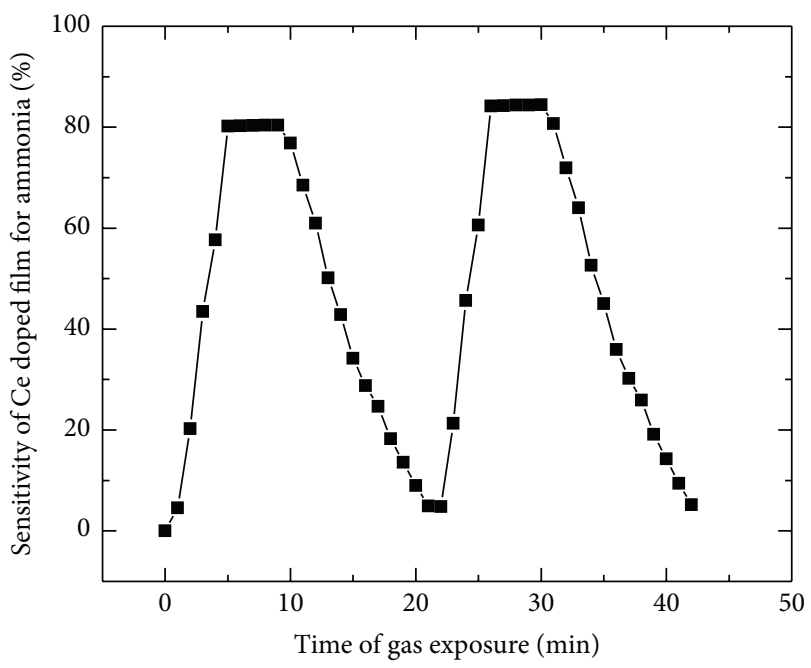

FIGURE 14: Response time of sensing film Ce doped $\mathrm{SnO}_{2}$ thin film towards ammonia.

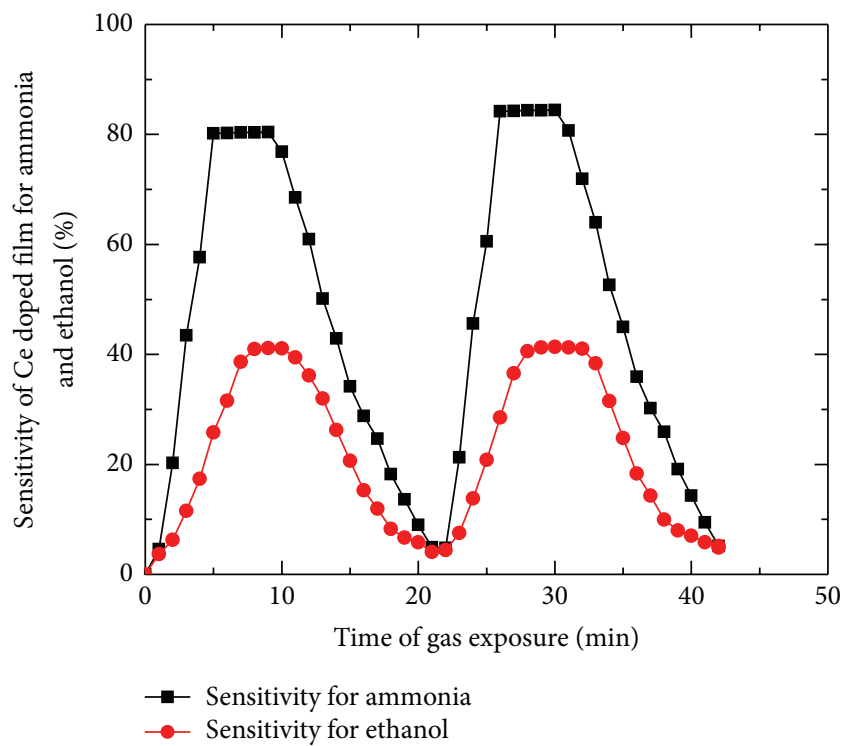

FIgURE 15: Response time of sensing film Ce doped $\mathrm{SnO}_{2}$ thin film towards ammonia and ethanol.

had a slightly sluggish behaviour towards ethanol as depicted in Figure 15. The sensor exhibited lesser sensitivity and higher response time towards ethanol. The sensor required almost 7 mins to reach a stable state. The sensor response declined rapidly with the decrement in the gas flow. The ethanol gas exposure was conducted with a cycle of 21 minutes to match that of the ammonia gas exposure cycle. When both responses were overlaid it is clearly obvious that $\mathrm{Ce}$ doped $\mathrm{SnO}_{2}$ thin film sensor showcased higher sensitivity and higher stability while sensing ammonia when compared to sensing ethanol. Even though the sensor required a little more time to return back to the initial response, it offered a better stability both while sensing and at no-flow conditions.

Short-term stability response studies of the thin film sensors need to be done to estimate the time for which 


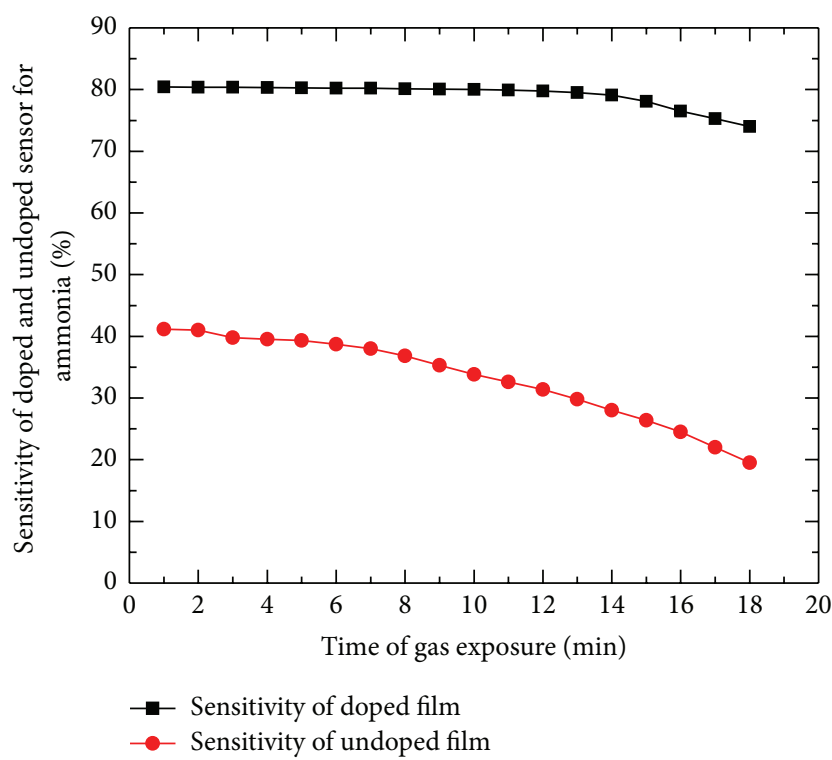

Figure 16: Sensing time response of Ce doped $\mathrm{SnO}_{2}$ thin film.

the sensors would give a stable output for a constant flow of gas and at constant optimum operating temperature. It was observed that $\mathrm{Ce}$ doped $\mathrm{SnO}_{2}$ film had a higher sensitivity factor towards ammonia at its optimum operating temperature of $325^{\circ} \mathrm{C}$ and the sensor had a stable response for a time period of around 14 minutes after which the response gets degraded. The response decreased more rapidly with the progress of time.

The undoped $\mathrm{SnO}_{2}$ thin film sensor had a comparatively lower sensitivity towards ammonia at its optimum operating temperature of $375^{\circ} \mathrm{C}$ and the sensor had a stable output only for a few minutes as shown in Figure 16. The response degraded gradually and much quicker than the doped film. Figure 15 depicts this change in sensitivity of both doped and undoped films when a fixed flow rate of ammonia of $10 \mathrm{~mL} / \mathrm{min}$ is allowed to flow over the substrate. The stable response time was acquired while passing ammonia at $500 \mathrm{ppm}$ concentration over the substrate. It could be inferred that the Ce doped $\mathrm{SnO}_{2}$ shows a maximum stability towards ammonia with respect to time and the film had stable response until 14 minutes from the flow initiation time. The pure $\mathrm{SnO}_{2}$ at various ppm had lesser sensitivity when compared to Ce doped $\mathrm{SnO}_{2}$ nanomaterial based thin film. It can be concluded that Ce doped $\mathrm{SnO}_{2}$ was having maximum sensitivity at lower temperature than pure $\mathrm{SnO}_{2}$ with longer duration of stability.

\section{Conclusion}

In summary, different concentrations of $2 \%$ Ce doped $\mathrm{SnO}_{2}$ were synthesized and characterized by SEM, FTIR, and XRD analyses. It was found that the $\mathrm{Ce}$ doped $\mathrm{SnO}_{2}$ exhibit good sensitivity and selectivity and fast response towards ammonia when compared to ethanol. All these results show that the Ce doped $\mathrm{SnO}_{2}$ nanomaterials are potential candidates for ammonia detection. Moreover $\mathrm{Ce}^{4+}$ doping can suppress the growth of large $\mathrm{SnO}_{2}$ crystallites and can lead to large nanospheres as shown in SEM. Furthermore it is equipped to detect the ammonia at low ppm. A new technique metal oxide semiconductor sensor for monitoring the gas leak in chemical industry has been developed. Sensing performance shows that the as-developed material could be used for sensing ammonia, which shows good sensitivity towards ammonia. All these observations demonstrate the promise of using Ce doped $\mathrm{SnO}_{2}$ as ammonia gas sensor in industrial and environmental monitoring.

\section{Competing Interests}

The authors declare that they have no competing interests.

\section{Acknowledgments}

The authors would like to express their sincere thanks to the Centre for Nanotechnology Research, VIT University, for its continued support in using the lab facilities.

\section{References}

[1] N. Hongsith, E. Wongrat, T. Kerdcharoen, and S. Choopun, "Sensor response formula for sensor based on $\mathrm{ZnO}$ nanostructures," Sensors and Actuators B: Chemical, vol. 144, no. 1, pp. 6772, 2010.

[2] S. B. Kondawar, S. P. Agrawal, S. H. Nimkar, H. J. Sharma, and P. T. Patil, "Conductive polyaniline-tin oxide nanocomposites for ammonia sensor," Advanced Materials Letters, vol. 3, no. 5, pp. 393-398, 2012.

[3] J. R. Brown, M. T. Cheney, P. W. Haycock, D. J. Houlton, A. C. Jones, and E. W. Williams, "The gas-sensing properties of tin oxide thin films deposited by metallorganic chemical vapor deposition," Journal of the Electrochemical Society, vol. 144, no. 1, pp. 295-299, 1997.

[4] A.-J. Galdikas, V. Jasutis, S. Kačiulis et al., "Peculiarities of surface doping with $\mathrm{Cu}$ in $\mathrm{SnO}_{2}$ thin film gas sensors," Sensors and Actuators, B: Chemical, vol. 43, no. 1-3, pp. 140-146, 1997.

[5] M. I. Ivanovskaya, P. A. Bogdanov, D. R. Orlik, A. C. Gurlo, and V. V. Romanovskaya, "Structure and properties of sol-gel obtained $\mathrm{SnO}_{2}$ and $\mathrm{SnO}_{2}$-Pd films," Thin Solid Films, vol. 296, no. 1-2, pp. 41-43, 1997.

[6] S. D. Bakrania and M. S. Wooldridge, "The effects of the location of au additives on combustion-generated $\mathrm{SnO}_{2}$ nanopowders for CO gas sensing," Sensors, vol. 10, no. 7, pp. 7002-7017, 2010.

[7] E. Comini, G. Faglia, G. Sberveglieri, Z. Pan, and Z. L. Wang, "Stable and highly sensitive gas sensors based on semiconducting oxide nanobelts," Applied Physics Letters, vol. 81, no. 10, pp. 1869-1871, 2002.

[8] P. Feng, Q. Wan, and T. H. Wang, "Contact-controlled sensing properties of flowerlike $\mathrm{ZnO}$ nanostructures," Applied Physics Letters, vol. 87, no. 21, Article ID 213111, pp. 1-3, 2005.

[9] D. Zhang, Z. Liu, C. Li et al., "Detection of $\mathrm{NO}_{2}$ down to ppb levels using individual and multiple $\operatorname{In}_{2} \mathrm{O}_{3}$ nanowire devices," Nano Letters, vol. 4, no. 10, pp. 1919-1924, 2004.

[10] L. Shi and H. Lin, "Preparation of band gap tunable $\mathrm{SnO}_{2}$ nanotubes and their ethanol sensing properties," Langmuir, vol. 27, no. 7, pp. 3977-3981, 2011. 
[11] B.-Y. Wei, M.-C. Hsu, P.-G. Su, H.-M. Lin, R.-J. Wu, and H.J. Lai, "A novel $\mathrm{SnO}_{2}$ gas sensor doped with carbon nanotubes operating at room temperature," Sensors and Actuators B: Chemical, vol. 101, no. 1-2, pp. 81-89, 2004.

[12] R. W. J. Scott, S. M. Yang, G. Chabanis, N. Coombs, D. E. Williams, and G. A. Ozin, "Tin dioxide opals and inverted opals: near-ideal microstructures for gas sensors," Advanced Materials, vol. 13, no. 19, pp. 1468-1472, 2001.

[13] Y. Zhang, J. P. Li, G. M. An, and X. L. He, "Highly porous $\mathrm{SnO}_{2}$ fibers by electrospinning and oxygen plasma etching and its ethanol-sensing properties," Sensors and Actuators B: Chemical, vol. 144, no. 1, pp. 43-48, 2010.

[14] G. X. Wang, J. S. Park, M. S. Park, and X. L. Gou, "Synthesis and high gas sensitivity of tin oxide nanotubes," Sensors and Actuators B: Chemical, vol. 131, no. 1, pp. 313-317, 2008.

[15] J. Zhang and L. Gao, "Synthesis and characterization of nanocrystalline tin oxide by sol-gel method," Journal of Solid State Chemistry, vol. 177, no. 4-5, pp. 1425-1430, 2004.

[16] A. S. Ahmed, A. Azam, M. M. Shafeeq, M. Chaman, and S. Tabassum, "Temperature dependent structural and optical properties of tin oxide nanoparticles," Journal of Physics and Chemistry of Solids, vol. 73, no. 7, pp. 943-947, 2012.

[17] M. Aziz, S. S. Abbas, W. R. W. Baharom, and W. Z. W. Mahmud, "Structure of $\mathrm{SnO}_{2}$ nanoparticles by sol-gel method," Materials Letters, vol. 74, pp. 62-64, 2012.

[18] S. Gnanam and V. Rajendran, "Synthesis of tin oxide nanoparticles by sol-gel process: effect of solvents on the optical properties," Journal of Sol-Gel Science and Technology, vol. 53, no. 3, pp. 555-559, 2010.

[19] C.-W. Lin, H.-I. Chen, T.-Y. Chen et al., "On an indiumtin-oxide thin film based ammonia gas sensor," Sensors and Actuators B: Chemical, vol. 160, no. 1, pp. 1481-1484, 2011.

[20] W. Chen, Q. Zhou, F. Wan, and T. Gao, "Gas sensing properties and mechanism of nano-SnO ${ }_{2}$-based sensor for hydrogen and carbon monoxide," Journal of Nanomaterials, vol. 2012, Article ID 612420, 9 pages, 2012.

[21] H. G. Zhang, Z. Y. Li, L. Liu et al., "Enhancement of hydrogen monitoring properties based on $\mathrm{Pd}-\mathrm{SnO}_{2}$ composite nanofibers," Sensors and Actuators B: Chemical, vol. 147, no. 1 , pp. 111-115, 2010.

[22] T. Lin, D. Lukas, and G. S. Bhat, "Nanofiber manufacture, properties, and applications," Journal of Nanomaterials, vol. 2013, Article ID 368191, 1 page, 2013.

[23] X. Song, Z. Wang, Y. Liu, C. Wang, and L. Li, "A highly sensitive ethanol sensor based on mesoporous $\mathrm{ZnO}-\mathrm{SnO}_{2}$ nanofibers," Nanotechnology, vol. 20, no. 7, Article ID 075501, 2009.

[24] G. Korotcenkov, I. Boris, V. Brinzari, S. H. Han, and B. K. Cho, "The role of doping effect on the response of $\mathrm{SnO}_{2}$-based thin film gas sensors: analysis based on the results obtained for Codoped $\mathrm{SnO}_{2}$ films deposited by spray pyrolysis," Sensors and Actuators B: Chemical, vol. 182, pp. 112-124, 2013.

[25] T. Tharsika, A. S. M. A. Haseeb, and M. F. M. Sabri, "Structural and optical properties of $\mathrm{ZnO}-\mathrm{SnO}_{2}$ mixed thin films deposited by spray pyrolysis," Thin Solid Films, vol. 558, pp. 283-288, 2014.

[26] L. Tan, L. Wang, and Y. Wang, "Hydrothermal synthesis of $\mathrm{SnO}_{2}$ nanostructures with different morphologies and their optical properties," Journal of Nanomaterials, vol. 2011, Article ID 529874, 10 pages, 2011.

[27] C. X. Guo, M. H. Cao, and C. W. Hu, "A novel and lowtemperature hydrothermal synthesis of $\mathrm{SnO}_{2}$ nanorods," Inorganic Chemistry Communications, vol. 7, no. 7, pp. 929-931, 2004.
[28] M. Aziz, S. Saber Abbas, and W. R. Wan Baharom, "Sizecontrolled synthesis of $\mathrm{SnO}_{2}$ nanoparticles by sol-gel method," Materials Letters, vol. 91, pp. 31-34, 2013.

[29] L. A. Patil, L. S. Sonawane, and D. G. Patil, "Room temperature ammonia gas sensing using $\mathrm{MnO}_{2}$-modified $\mathrm{ZnO}$ thick film resistors," Journal of Modern Physics, vol. 2, no. 10, pp. 1215-1221, 2011.

[30] H.-R. Kim, K.-I. Choi, J.-H. Lee, and S. A. Akbar, "Highly sensitive and ultra-fast responding gas sensors using selfassembled hierarchical $\mathrm{SnO}_{2}$ spheres," Sensors and Actuators, B: Chemical, vol. 136, no. 1, pp. 138-143, 2009.

[31] H. Z. Wang, J. B. Liang, H. Fan et al., "Synthesis and gas sensitivities of $\mathrm{SnO}_{2}$ nanorods and hollow microspheres," Journal of Solid State Chemistry, vol. 181, no. 1, pp. 122-129, 2008.

[32] P. Sun, W. Zhao, Y. Cao, Y. Guan, Y. Sun, and G. Lu, "Porous $\mathrm{SnO}_{2}$ hierarchical nanosheets: hydrothermal preparation, growth mechanism, and gas sensing properties," Crystal Engineering Communications, vol. 13, no. 11, pp. 3718-3724, 2011.

[33] B. Esfandyarpour, S. Mohajerzadeh, S. Famini, A. Khodadadi, and E. Asl Soleimani, "High sensitivity Pt-doped $\mathrm{SnO}_{2}$ gas sensors fabricated using sol-gel solution on micromachined (1 0 0) Si substrates," Sensors and Actuators B: Chemical, vol. 100, no. 1-2, pp. 190-194, 2004.

[34] A. P. Maciel, P. N. Lisboa-Filho, E. R. Leite et al., "Microstructural and morphological analysis of pure and Ce-doped tin dioxide nanoparticles," Journal of the European Ceramic Society, vol. 23, no. 5, pp. 707-713, 2003.

[35] I. T. Weber, A. Valentini, L. F. D. Probst, E. Longo, and E. R. Leite, "Influence of noble metals on the structural and catalytic properties of Ce-doped $\mathrm{SnO}_{2}$ systems," Sensors and Actuators B: Chemical, vol. 97, no. 1, pp. 31-38, 2004.

[36] A. Gurlo, "Nanosensors: towards morphological control of gas sensing activity. $\mathrm{SnO}_{2}, \mathrm{In}_{2} \mathrm{O}_{3}, \mathrm{ZnO}$ and $\mathrm{WO}_{3}$ case studies," Nanoscale, vol. 3, no. 1, pp. 154-165, 2011.

[37] L. Li, C. Zhang, and W. Chen, "Fabrication of $\mathrm{SnO}_{2}$ $\mathrm{SnO}$ nanocomposites with $\mathrm{p}-\mathrm{n}$ heterojunctions for the lowtemperature sensing of $\mathrm{NO}_{2}$ gas," Nanoscale, vol. 7, no. 28, pp. 12133-12142, 2015.

[38] J. Wang, F. Yang, X. Wei et al., "Controlled growth of conical nickel oxide nanocrystals and their high performance gas sensing devices for ammonia molecule detection," Physical Chemistry Chemical Physics, vol. 16, no. 31, pp. 16711-16718, 2014.

[39] B. Timmer, W. Olthuis, and A. Van Den Berg, "Ammonia sensors and their applications-a review," Sensors and Actuators B: Chemical, vol. 107, no. 2, pp. 666-677, 2005.

[40] A. Teeramongkonrasmee and M. Sriyudthsak, "Methanol and ammonia sensing characteristics of sol-gel derived thin film gas sensor," Sensors and Actuators B: Chemical, vol. 66, no. 1, pp. 256-259, 2000.

[41] Y.-D. Wang, X.-H. Wu, Q. Su, Y.-F. Li, and Z.-L. Zhou, "Ammonia-sensing characteristics of $\mathrm{Pt}$ and $\mathrm{SiO}_{2}$ doped $\mathrm{SnO}_{2}$ materials," Solid-State Electronics, vol. 45, no. 2, pp. 347-350, 2001.

[42] I. Rawal, "Facial synthesis of hexagonal metal oxide nanoparticles for low temperature ammonia gas sensing applications," RSC Advances, vol. 5, no. 6, pp. 4135-4142, 2015.

[43] K. K. Makhija, A. Ray, R. M. Patel, U. B. Trivedi, and H. N. Kapse, "Indium oxide thin film based ammonia gas and ethanol vapour sensor," Bulletin of Materials Science, vol. 28, no. 1, pp. 917, 2005. 
[44] A. L. Kukla, Yu. M. Shirshov, and S. A. Piletsky, "Ammonia sensors based on sensitive polyaniline films," Sensors and Actuators B: Chemical, vol. 37, no. 3, pp. 135-140, 1996.

[45] E. C. Dickey, O. K. Varghese, K. G. Ong, D. Gong, M. Paulose, and C. A. Grimes, "Room temperature ammonia and humidity sensing using highly ordered nanoporous alumina films," Sensors, vol. 2, no. 3, pp. 91-110, 2002.

[46] M. Saroch, S. Srivastava, D. Fink, and A. Chandra, "Room temperature ammonia gas sensing using mixed conductor based TEMPOS structures," Sensors, vol. 8, no. 10, pp. 63556370, 2008.

[47] D. J. Wales, J. Grand, V. P. Ting et al., "Gas sensing using porous materials for automotive applications," Chemical Society Reviews, vol. 44, no. 13, pp. 4290-4321, 2015.

[48] R. Moos, R. Müller, C. Plog et al., "Selective ammonia exhaust gas sensor for automotive applications," Sensors and Actuators B: Chemical, vol. 83, no. 1-3, pp. 181-189, 2002.

[49] H. P. Hong, J. H. Kim, C. J. Lee, and N. K. Min, "In-plane impedancemetric ammonia sensing of solution-deposited, highly semiconductor-enriched single-wall carbon nanotube submonolayer network gas sensors," Sensors and Actuators B: Chemical, vol. 220, pp. 27-32, 2015.

[50] N. S. Arul, D. Mangalaraj, R. Ramachandran, A. N. Grace, and J. I. Han, "Fabrication of $\mathrm{CeO}_{2} / \mathrm{Fe}_{2} \mathrm{O}_{3}$ composite nanospindles for enhanced visible light driven photocatalysts and supercapacitor electrodes," Journal of Material Chemistry A, vol. 3, no. 29, pp. 15248-15258, 2015.

[51] J. Z. Ou, W. Ge, B. Carey et al., "Physisorption-based charge transfer in two-dimensional $\mathrm{SnS}_{2}$ for selective and reversible $\mathrm{NO}_{2}$ gas sensing," ACS Nano, vol. 9, no. 10, pp. 10313-10323, 2015. 


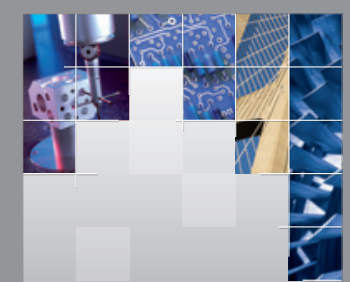

\section{Enfincering}
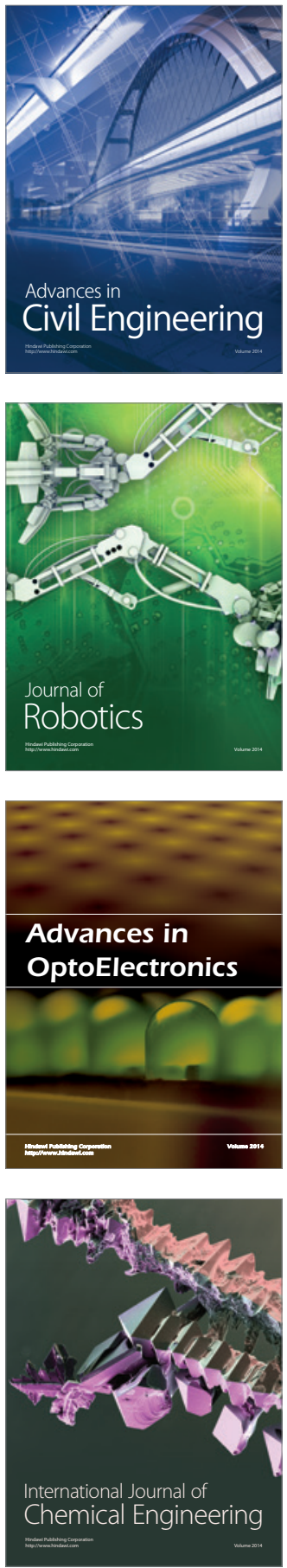

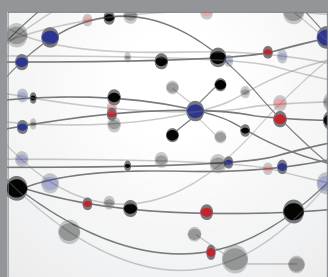

The Scientific World Journal

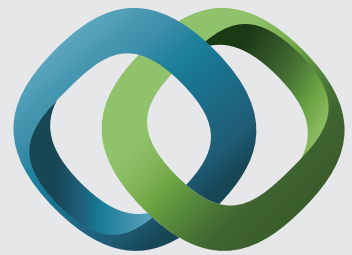

\section{Hindawi}

Submit your manuscripts at

http://www.hindawi.com
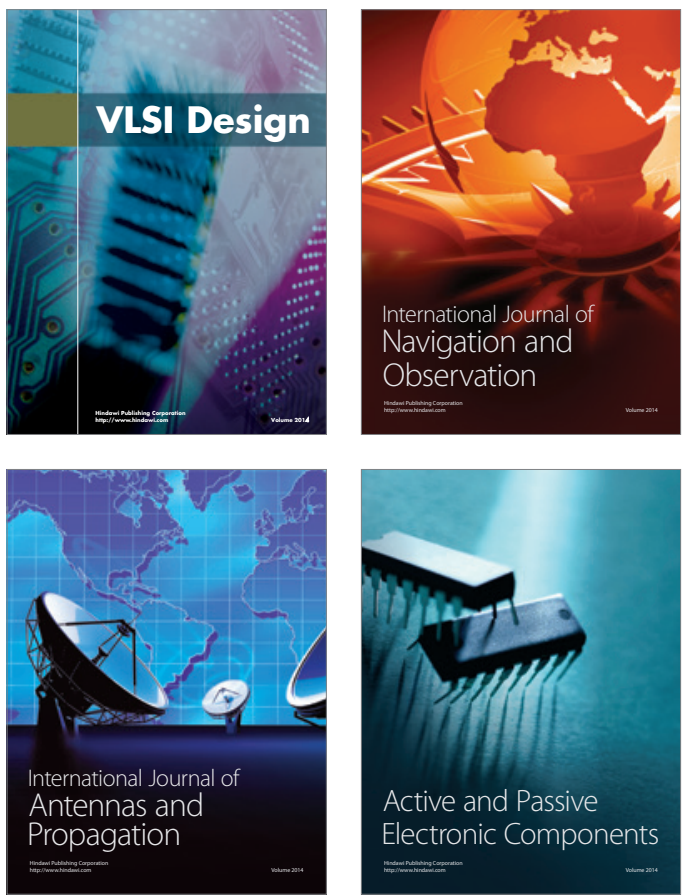
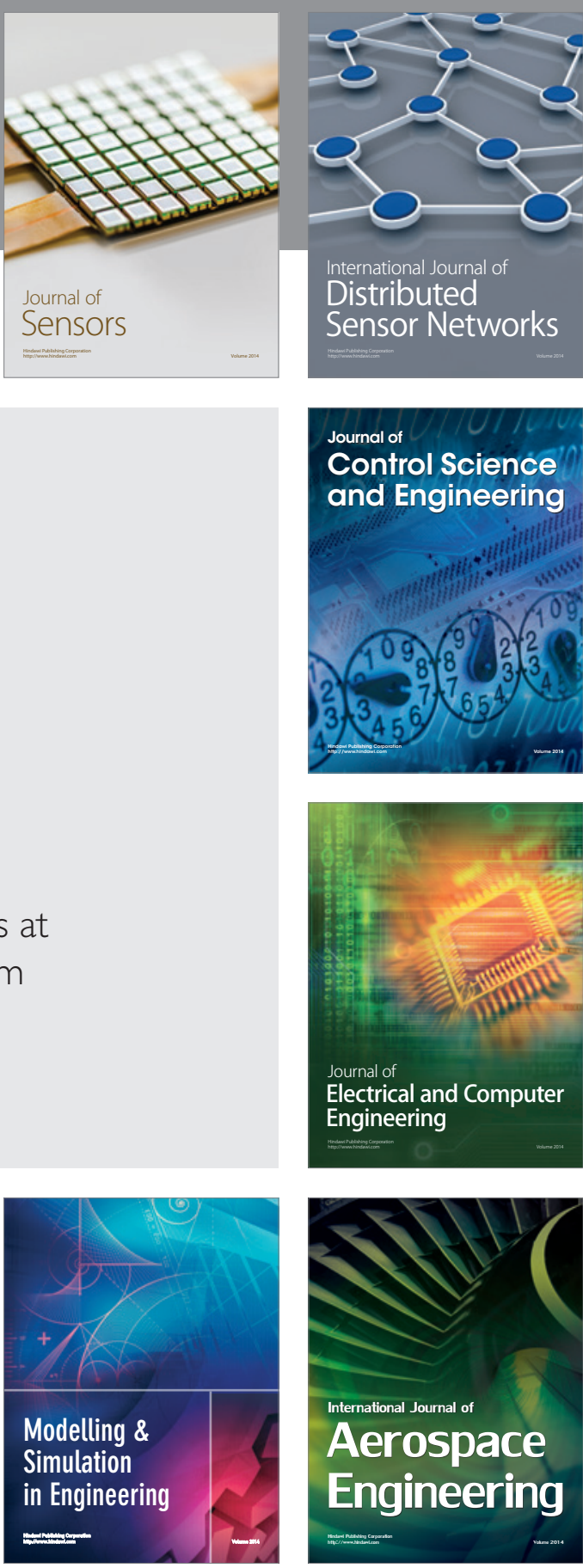

International Journal of

Distributed

Sensor Networks

Journal of

Control Science

and Engineering
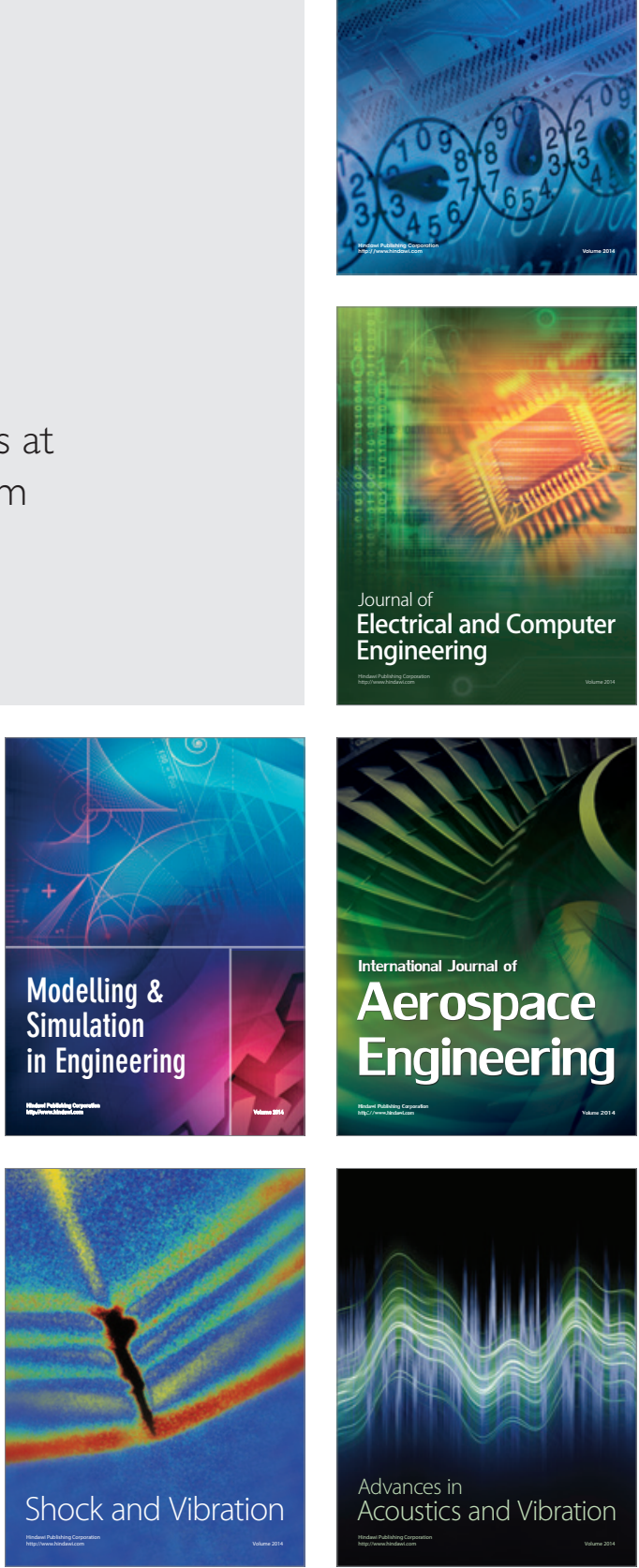